\title{
Attribution analysis based on Budyko hypothesis for land evapotranspiration change in the Loess Plateau, China
}

\author{
HE Guohua ${ }^{1,2}$, ZHAO Yong ${ }^{1,2 *}$, WANG Jianhua ${ }^{1,2}$, GAO Xuerui ${ }^{3}$, HE Fan ${ }^{1,2}$, LI Haihong ${ }^{1,2}$, \\ ZHAI Jiaqi ${ }^{1,2}$, WANG Qingming ${ }^{1,2}$, ZHU Yongnan ${ }^{1,2}$

\footnotetext{
${ }^{1}$ State Key Laboratory of Simulation and Regulation of Water Cycle in River Basin, Beijing 100038, China;

${ }^{2}$ China Institute of Water Resources and Hydropower Research, Beijing 100038, China;

${ }^{3}$ Institute of Soil and Water Conservation, Northwest A\&F University, Yangling 712100, China
}

\begin{abstract}
Land evapotranspiration (ET) is an important process connecting soil, vegetation and the atmosphere, especially in regions that experience shortage in precipitation. Since 1999, the implementation of a large-scale vegetation restoration project has significantly improved the ecological environment of the Loess Plateau in China. However, the quantitative assessment of the contribution of vegetation restoration projects to long-term ET is still in its infancy. In this study, we investigated changes in land ET and associated driving factors from 1982 to 2014 in the Loess Plateau using Budyko-based partial differential methods. Overall, annual ET slightly increased by $0.28 \mathrm{~mm} / \mathrm{a}$ and there were no large fluctuations after project implementation. An attribution analysis showed that precipitation was the driving factor of inter-annual variability of land ET throughout the study period; the average impacts of precipitation, potential evapotranspiration, and vegetation restoration on ET change were $61.5 \%, 11.5 \%$ and $26.9 \%$, respectively. These results provide an improved understanding of the relationship between vegetation condition change and climate variation on terrestrial ET in the study area and can support future decision-making regarding water resource availability.
\end{abstract}

Keywords: climate change; vegetation; evapotranspiration; control factor; arid region

Citation: HE Guohua, ZHAO Yong, WANG Jianhua, GAO Xuerui, LI Haihong, ZHAI Jiaqi, WANG Qingming, ZHU Yongnan. 2019. Attribution analysis based on Budyko hypothesis for land evapotranspiration change in the Loess Plateau, China. Journal of Arid Land, 11(6): 939-953. https://doi.org/ 10.1007/s40333-019-0107-5

\section{Introduction}

Land evapotranspiration (ET) is a key process in the climatic and biogeochemical cycles of terrestrial ecosystems, forming a nexus of the carbon, energy and water cycles (Jung et al., 2010). Changes in terrestrial ET help control surface temperature and latent heat, thus significantly reflecting regional and global climate characteristics (Meng et al., 2009; Chirouze et al., 2013). Such changes also influence terrestrial surface water and groundwater availability in lakes, rivers, reservoirs and underground aquifers (Zhang et al., 2016). Moreover, soil moisture is a key factor for vegetation growth and is closely related to ET. According to previous studies, there are obvious differences in soil moisture among different vegetation types, and the challenge of vegetation restoration to soil water deficit in arid and semi-arid regions is a matter of debate

*Corresponding author: ZHAO Yong (E-mail: zhaoyong@iwhr.com)

Received 2018-09-03; revised 2019-07-08; accepted 2019-08-09

(C) Xinjiang Institute of Ecology and Geography, Chinese Academy of Sciences, Science Press and Springer-Verlag GmbH Germany, part of Springer Nature 2019 
(Fang et al., 2016; Zhang et al., 2016; Zhao et al., 2018). Global terrestrial ET returns about 60\% of annual terrestrial precipitation to the atmosphere (Oki and Kanae, 2006). However, due to the intensification of climate change and the enhancement of human activities, global actual ET began to decline in recent years, which has led to a huge change in global precipitation, runoff and soil moisture (Feng et al., 2017). Consequently, quantitative estimation of ET and understanding its key controlling factors is a basic research issue.

Quantitatively determining the impact of climate change and human activities on ET has always been topic of interest in the study of terrestrial cycling processes. Liu and Yang (2010) used the simple two-parameter steady-state model to analyze the influence of climate change on ET in China's Yellow River Basin, suggesting that precipitation was the controlling factor for ET change. However, in almost the same region, Feng et al. (2016) analyzed the contributors to ET change using spatio-temporal correlation analysis, showing that human activities rather than climatic variation primarily caused the rise in ET. Ning et al. (2017) analyzed the contribution of vegetation coverage and climate factors to actual ET in the Loess Plateau using Fu's equation. They found that ET changes in 4 of 13 sub-basins of Loess Plateau were controlled by vegetation coverage during 1981-2012, while in the other sub-basins, the dominant factor was precipitation. The relationship between precipitation and actual ET was also studied in the Loess Plateau using spatial correlation analysis (Gao et al., 2016). Research findings indicated that both regional precipitation and actual ET showed a significant increasing trend. However, the rate of increasing of precipitation was greater than that of actual ET during the study period. Droogers (2000) used the soil water atmosphere plant model to estimate ET in Turkey's Gediz basin, concluding that changes in soil characteristics (influenced by cultivation) were a key factor affecting ET. Fang et al. (2012) presented a complex algorithm based on two hydrologic models (Xinanjiang and SWAT) used to estimate daily spatial ET.

Overall, hydrologic models and statistical methods are the two most common evaluation methods used to quantitatively determine the contribution of climate change and human activities to ET change. Hydrological modeling can effectively separate the two processes, but the complex physical mechanism requires a large number of accurate data to be input into the model. This is not only time consuming, but also creates uncertainty in calibration and verification (Nash and Gleick, 1991). In comparison, statistical methods are relatively simple, but lack a physical mechanism. In recent years, partial differential methods based on the Budyko hypothesis have been widely used in the contribution analysis of ET changes, because of their relatively simple calculation process and physical mechanism; these methods have proven to be credible and reasonable (Roderick and Farquhar, 2011; Wu et al., 2017).

The Loess Plateau accounts for $6.6 \%$ of China's total land area and sustains $8.5 \%$ of the population (Fu et al., 2011). Because of the intensified human activities (e.g., crop agriculture and coal mining) and adverse environmental conditions (e.g., loose soil, high precipitation intensity and sparse vegetation), this region suffers from severe soil erosion with rates mostly higher than $5000 \mathrm{t} /\left(\mathrm{km}^{2} \cdot \mathrm{a}\right)$, reaching $2.5 \times 10^{4} \mathrm{t} /\left(\mathrm{km}^{2} \cdot \mathrm{a}\right)$ (Zhao et al., 2013). To solve these serious ecological problems, the Chinese government launched the largest vegetation restoration project in Chinese history, called the Grain for Green (GFG) project in 1999, which involves working to return cropland on steep slopes to forest and grassland using a government payment scheme that engages millions of rural households as core project implementation agents (Lü et al., 2012; Feng et al., 2013). However, the GFG project will affect underlying surface characteristics in the Loess Plateau, and have both direct and indirect impacts on the local water and energy budget (Zhang et al., 2001). Since the implementation of the GFG project, concerns have been raised that rapidly increasing vegetation cover could greatly increase ET and thus result in water shortages (Zhang et al., 2016). Consequently, quantitative estimations of ET change in the Loess Plateau and further delineation of the main factors driving ET changes can improve the region's ecological and water-resource sustainability. To better evaluate the contribution of the GFG project on ET, we divided the entire study period into two sub-periods according to project implementation time: before implementation (1982-1999) (referred to as pre-GFG) and during implementation (20002014) (referred to as post-GFG). 
In this study, we aimed to quantitatively evaluate ET and more precisely determine its main controlling factors in the Loess Plateau by: (1) estimating and validating annual ET in the Loess Plateau from 1982 to 2014; (2) quantitatively analyzing the impacts of climate change and human activities on ET changes using the Budyko-based partial differential method; and (3) discussing the reliability of our research results by comparison with previous studies.

\section{Study area and methods}

\subsection{Study area}

The Loess Plateau is located in the upper and middle reaches of the Yellow River Basin $\left(33^{\circ} 43^{\prime}-\right.$ $41^{\circ} 16^{\prime} \mathrm{N}, 100^{\circ} 54^{\prime}-114^{\circ} 33^{\prime} \mathrm{E}$ ), covering an area of approximately $6.28 \times 10^{5} \mathrm{~km}^{2}$ over an elevation range of $85-5147 \mathrm{~m}$ (Fig. 1). The mean annual precipitation in this region is $421 \mathrm{~mm}(1960$ 2010 ), of which $60 \%-70 \%$ occurs between June and September in the form of high-intensity rainstorms. The Loess Plateau is a typical water-deficient area. The water resources here account for only $2 \%$ of the Chinese total, but their utilization ratio is as high as $70 \%$, which is far greater than the internationally recognized water utilization threshold (Gao et al., 2009). The main soil types in the Loess Plateau are Lossiah and dark Lossiah, which are loose in structure and easily eroded. Land uses are primarily cropland, grassland, forest and sand land.

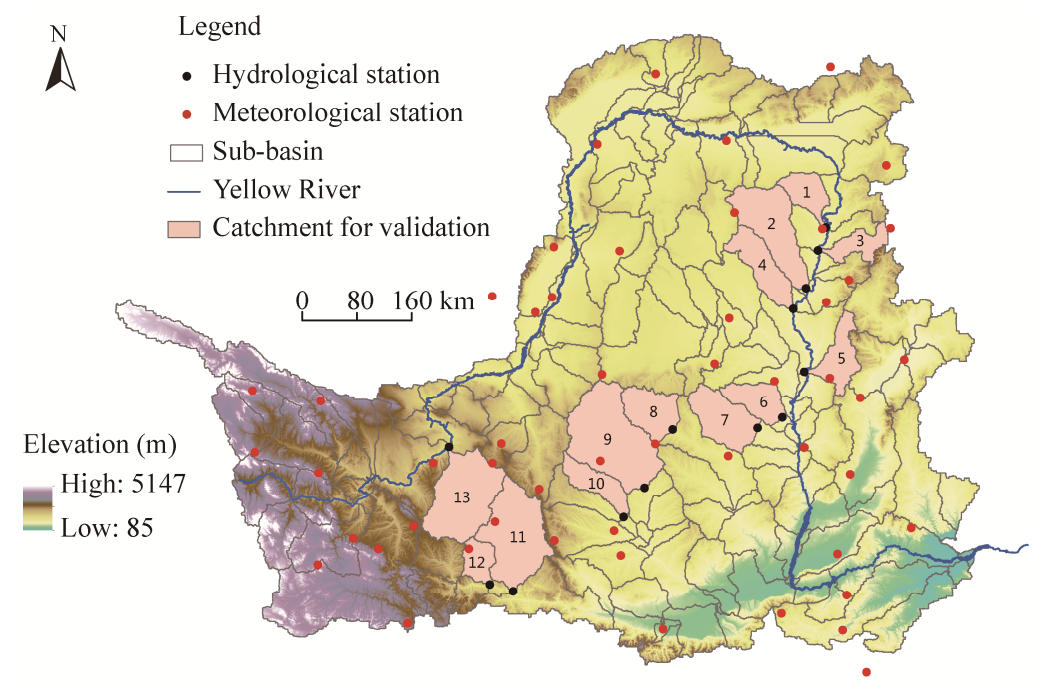

Fig. 1 Distribution of the hydrological stations, meteorological stations and thirteen catchments used for validation on the Loess Plateau, China. Information about catchments and corresponding hydrological stations were detailed in Table S1.

\subsection{Data sources}

We used two categories of data in this study, the first category involves the parameters required to estimate ET using the Budyko hypothesis, which include daily meteorological data (precipitation, minimum temperature, maximum temperature, relative humidity, atmospheric pressure, wind speed and sunshine hours), soil types and properties, high-resolution digital elevations, and long time series (1982-2014) vegetation coverage data. Daily meteorological data from 52 meteorological stations distributed in the study area (Fig. 1) were downloaded from the National Meteorological Information Center (http://data.cma.cn/). Soil data were downloaded from China's Resource and Environment Data Cloud Platform (http://www.resdc.cn). Digital elevation data were downloaded from the United States' Land Processes Distributed Active Archive Center (http://www.gdem.aster) at $30 \mathrm{~m}$ spatial resolution. Vegetation coverage data were downloaded from NASA's Earth Exchange (https://ecocast.arc.nasa.gov) at $8 \mathrm{~km}$ spatial resolution and $15 \mathrm{~d}$ temporal resolution. The second data category involved observed runoff data used to validate the 
reliability of the ET results; these were recorded by 13 hydrological stations within the Loess Plateau (Fig. 1) and acquired from China's National Data Sharing Infrastructure of Earth System Science (http://www.geodata.cn/). All daily data (such as meteorological data and runoff data) and $15 \mathrm{~d}$ data (such as NDVI data) were calculated to obtain a monthly average, which was then used to obtain annual values in every year. The changing trend of the time series data was then analyzed using the Mann-Kendall test (Zhang et al., 2016).

\subsection{Methods}

\subsubsection{Evapotranspiration estimation using the Budyko hypothesis}

The Budyko hypothesis assumes that the annual scale of land ET can be expressed as a function of available water and energy (Budyko, 1961, 1969). However, the function introduced by Budyko is just a conceptual equation that cannot be directly used for calculations. In 2008, Yang et al. (2008) used dimensional analysis and mathematical reasoning to derive a water-energy coupling equation based on the Budyko hypothesis; the use of this equation has proven to be feasible in many Chinese basins (Yang et al., 2006; Yang et al., 2007). Yang's equation is expressed as:

$$
\mathrm{ET}=\frac{P \times \mathrm{ET}_{0}}{\left(P^{n}+\mathrm{ET}_{0}^{n}\right)^{1 / n}},
$$

where ET is the annual terrestrial land evapotranspiration $(\mathrm{mm}) ; P$ is the annual precipitation $(\mathrm{mm}) ; \mathrm{ET}_{0}$ is the annual potential evapotranspiration $(\mathrm{mm})$; and $n$ represents the catchment landscape characteristics as a dimensionless metric. The information about meteorological stations in the study area was detail in Table S2.

The parameter $n$ is important in Yang's equation, as it is mainly related to the regional properties of soil, topography, and vegetation. Based on statistical analysis of long-term meteorological and runoff data, Yang et al. (2009) proposed a semi-empirical equation to calculate $n$ in the Yellow River Basin (Eq. 2).

$$
\begin{gathered}
n=5.755\left(\frac{k_{\mathrm{s}}}{i_{\mathrm{r}}}\right)^{-0.368} M^{0.292} \exp (-5.428 \tan \beta), \\
i_{\mathrm{r}}=\frac{P}{N \times 24}, \\
M=\frac{\mathrm{NDVI}-\mathrm{NDVI}_{\text {min }}}{\mathrm{NDVI}-\mathrm{NDVI}_{\max }},
\end{gathered}
$$

where $k_{\mathrm{s}}$ is the soil saturated conductivity $(\mathrm{mm} / \mathrm{h}) ; i_{\mathrm{r}}$ is the annual precipitation intensity, with $N$ as the total number of rainy days in the year; $k_{\mathrm{s}} / i_{\mathrm{r}}$ is the relative soil infiltration capacity; $M$ represents vegetation coverage; NDVI is the normalized difference vegetation index, and $\mathrm{NDVI}_{\min }$ and $\mathrm{NDVI}_{\max }$ represent the maximum and minimum values of NDVI during the year, respectively; and $\tan \beta$ indicates the average slope of the catchment. As soil condition and topography are relatively stable in a given catchment, changes in $n$ within a catchment are mainly attributed to changes in vegetation (Yang et al., 2015). In this study, we used NDVI as an indicator of vegetation changes.

Generally, $\mathrm{ET}_{0}$ is calculated using the Penman-Monteith $(\mathrm{P}-\mathrm{M})$ equation, which is based on the principles of energy balance and aerodynamics. P-M equation has a complete theoretical basis and high accuracy, which was recommended by the United Nations Food and Agriculture Organization (FAO) in 1998, and is now widely used around the world. The P-M equation is calculated as:

$$
\mathrm{ET}_{0}=\frac{0.408 \Delta\left(R_{n}-G\right)+\gamma \frac{900}{273+T} u_{2}\left(e_{\mathrm{a}}-e_{\mathrm{d}}\right)}{\Delta+\gamma\left(1+0.34 u_{2}\right)},
$$

where $\mathrm{ET}_{0}$ is the potential evapotranspiration $(\mathrm{mm}) ; \Delta$ is the slope of the vapor pressure curve 
$\left(\mathrm{kPa} /{ }^{\circ} \mathrm{C}\right) ; \gamma$ is the psychometric constant $\left(\mathrm{kPa} /{ }^{\circ} \mathrm{C}\right) ; T$ is the mean daily air temperature $\left({ }^{\circ} \mathrm{C}\right) ; e_{\mathrm{a}}$ is the saturation vapor pressure $(\mathrm{kPa}) ; R_{n}$ is the net radiation at the surface $\left(\mathrm{MJ} /\left(\mathrm{m}^{2} \cdot \mathrm{d}\right)\right) ; e_{\mathrm{d}}$ is the actual atmospheric water vapor pressure $(\mathrm{kPa})$; $G$ is the all-wave ground heat flux $\left(\mathrm{MJ} /\left(\mathrm{m}^{2} \cdot \mathrm{d}\right)\right)$; and $u_{2}$ is the daily average wind speed at $2 \mathrm{~m}$ height $(\mathrm{m} / \mathrm{s})$.

2.3.2 Quantifying contributions to ET changes

Due to $P, \mathrm{ET}_{0}$ and $n$ are always assuming independent in Equation 1 (Xu et al., 2014). Thus, Equation 1 can be rewritten as $\mathrm{ET}=f\left(P, \mathrm{ET}_{0}, n\right)$ and the total differential of actual evaporation can be written as:

$$
\frac{d \mathrm{ET}}{d t}=\frac{\partial \mathrm{ET}}{\partial P} \frac{d P}{d t}+\frac{\partial \mathrm{ET}}{\partial \mathrm{ET}_{0}} \frac{d \mathrm{ET}_{0}}{d t}+\frac{\partial \mathrm{ET}}{\partial n} \frac{d n}{d t},
$$

where $\frac{d \mathrm{ET}}{d t}, \frac{d P}{d t}, \frac{d \mathrm{ET}_{0}}{d t}$, and $\frac{d n}{d t}$ represent changes in $\mathrm{ET}, P, \mathrm{ET}_{0}$ and $n$, respectively, for a given time interval.

The respective partial differentials of Equation 4 were given by Roderick and Farquhar (2011), whose equations (Eqs. 7-9) form a basis for understanding how changes in climate $\left(P, \mathrm{ET}_{0}\right)$ and vegetation affect ET:

$$
\begin{gathered}
\frac{\partial \mathrm{ET}}{\partial P}=\frac{\mathrm{ET}}{P}\left(\frac{\mathrm{ET}_{0}^{n}}{P^{n}+\mathrm{ET}_{0}^{n}}\right), \\
\frac{\partial \mathrm{ET}}{\partial \mathrm{ET}_{0}^{n}}=\frac{\mathrm{ET}}{\mathrm{ET}_{0}}\left(\frac{P^{n}}{P^{n}+\mathrm{ET}_{0}^{n}}\right), \\
\frac{\partial \mathrm{ET}}{\partial n}=\frac{\mathrm{ET}}{n}\left(\frac{\ln \left(P^{n}+\mathrm{ET}_{0}^{n}\right)}{n}+\frac{P^{n} \ln P+\mathrm{ET}_{0}^{n} \ln \mathrm{ET}_{0}}{P^{n}+\mathrm{ET}_{0}^{n}}\right) .
\end{gathered}
$$

\subsubsection{Validating the estimated ET}

A region's water balance equation can be described as:

$$
P=R+\mathrm{ET}+\Delta G+\Delta S+\Delta I
$$

where $P$ is the precipitation in a given period $(\mathrm{mm}) ; R$ is the equivalent runoff depth $(\mathrm{mm})$; ET is the actual evapotranspiration $(\mathrm{mm}) ; \Delta G$ is the amount of deep groundwater percolation $(\mathrm{mm}) ; \Delta S$ is the change in soil water storage $(\mathrm{mm})$; and $\Delta I$ is the amount of water intercepted by reservoirs $(\mathrm{mm})$.

However, the water flux between the unsaturated zone and groundwater within the Loess Plateau is too small to be considered and groundwater is also difficult to utilize in this region due to the depth of the unsaturated zone (ranging from 50 to $200 \mathrm{~m}$ ) (Zhang et al., 2014). Moreover, at a multi-year average scale, changes in soil water storage and reservoir storage are negligible. Thus, precipitation is the main input source of water within the Loess Plateau, such that the long-term water balance equation can be simplified as:

$$
\mathrm{ET}=P-R,
$$

Based on Equation 11, we can use regional hydrologic and precipitation data to validate the estimated regional ET in the corresponding catchments. The details of the catchments for validation and corresponding hydrological stations are shown in the supplement data (Table S1).

\section{Results and discussion}

\subsection{Validation of the estimated ET}

To test the reliability of the estimated ET calculated by Equation 1 (Yang et al., 2009), this study analyzed the estimated ET and observed ET in the 13 catchments based on the corresponding hydrological stations in the Loess Plateau during 1982-2014. The comparisons of the estimated and observed ET in the 13 catchments indicated that the Budyko hypothesis generally performed 
well in the study area. Particularly, estimated ET values were mostly slightly lower than observed ET values (except in the Gaojiachuan catchment), with a mean bias of $-37.3 \mathrm{~mm} / \mathrm{a}$ (Fig. 2). This result is credible because Yang's model does not consider the contribution of agricultural irrigation, urban greenland irrigation and reservoirs to land ET. Overall, the calculation results for regional ET met the requirements of this study for reliability and acceptability.

\subsection{Spatio-temporal variations of $P$, ET $_{0}, \mathrm{NDVI}$, and ET}

\subsubsection{Temporal variations}

The mean annual precipitation over the Loess Plateau from 1982 to 2014 was $430 \mathrm{~mm}$, decreasing at a rate of $0.2 \mathrm{~mm} / \mathrm{a}(Z=-0.23, P>0.05)$ (Fig. 3). During 1982-1999, the mean annual precipitation was $429 \mathrm{~mm}$, decreasing at a rate of $3.1 \mathrm{~mm} / \mathrm{a}(Z=-1.14, P>0.05)$; however, precipitation significantly increased for 2000-2014 ( $\mathrm{Z}=1.48, P<0.05)$ with an average increase rate of $1.9 \mathrm{~mm} / \mathrm{a}$.

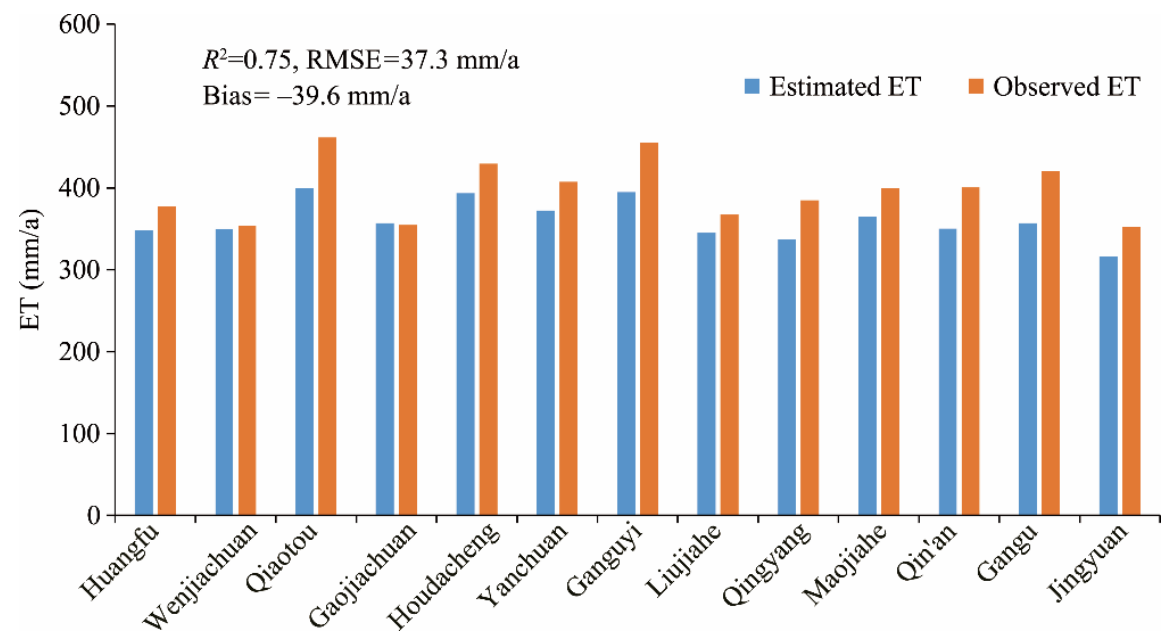

Fig. 2 Validation of the estimated evapotranspiration (ET) by comparing the estimated multi-year average ET (1982-2014) and observed ET in 13 catchments within the Loess Plateau (bias defined as estimated mean minus observed mean)

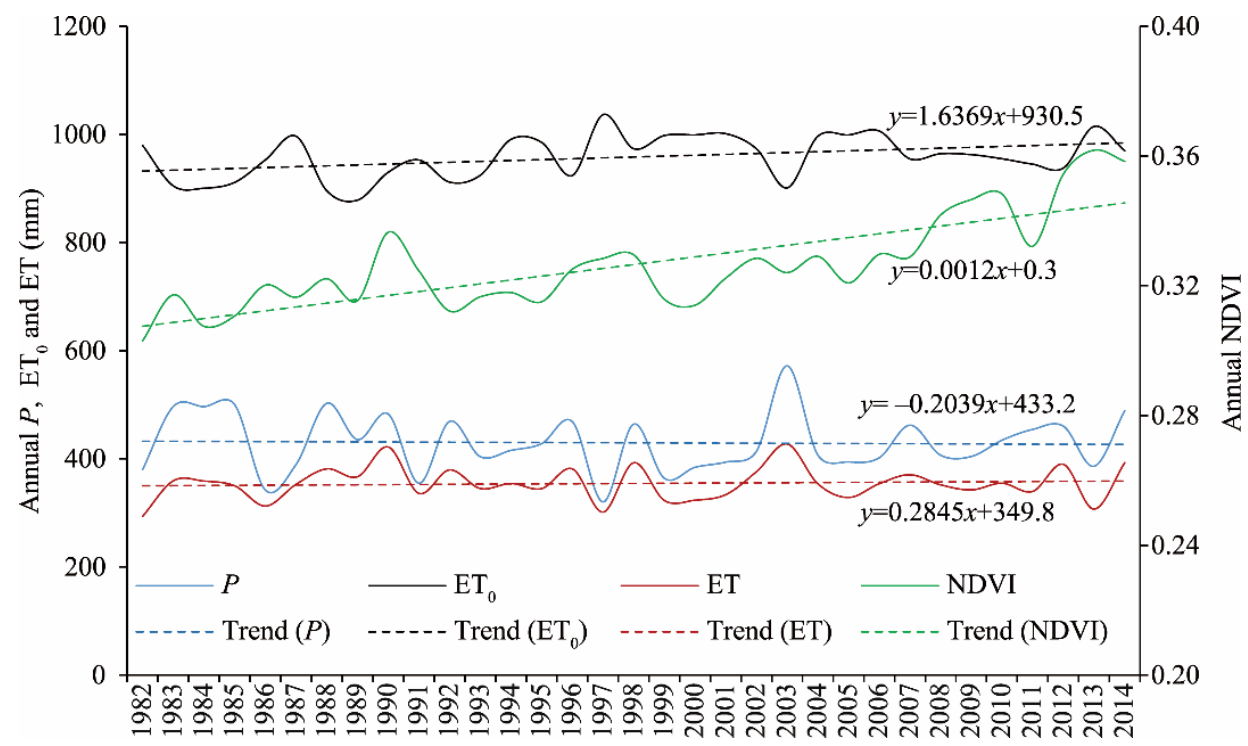

Fig. 3 Change trends for mean annual precipitation $(P)$, annual potential evapotranspiration $\left(\mathrm{ET}_{0}\right)$, normalized difference vegetation index (NDVI), and annual actual ET from 1982 to 2014

The annual $\mathrm{ET}_{0}$ over the Loess Plateau showed a clear increasing trend during 1982-2014, with 
a rising rate of $1.6 \mathrm{~mm} / \mathrm{a}(\mathrm{Z}=2.03, P<0.05)$. Contrary to precipitation, annual $\mathrm{ET}_{0}$ for $1982-1999$ clearly increased at an average rate of $3.9 \mathrm{~mm} / \mathrm{a}(Z=1.89, P<0.05)$. However, for 2000-2014, $\mathrm{ET}_{0}$ slightly decreased at a rate of $1.3 \mathrm{~mm} / \mathrm{a}(\mathrm{Z}=1.09, P>0.05)$.

The annual average NDVI over the Loess Plateau for 1982-2014 increased from 0.303 to 0.358 . During 1982-1999, NDVI clearly increased at a rate of $0.0008 / \mathrm{a}(\mathrm{Z}=2.2, P<0.05)$, while the increase for 2000-2014 was almost four times higher $(Z=4.1, P<0.05)$.

Although the change trends of $P$ and $\mathrm{ET}_{0}$ were inconsistent in both periods, the ET showed a slight increasing trend throughout. For 1982-1999, the annual mean ET was $353.2 \mathrm{~mm}$ with an increase rate of $0.69 \mathrm{~mm} / \mathrm{a}(Z=0.23, P>0.05)$. For $2000-2014$, the annual mean ET was $356.5 \mathrm{~mm}$ with an increase rate of $0.25 \mathrm{~mm} / \mathrm{a}(Z=0.49, P>0.05)$. Over the entire period, the annual average ET was $354.7 \mathrm{~mm}$ with relatively stable inter-annual fluctuations. Based on the patterns shown in Figure 3, we concluded that over $80 \%$ of precipitation during the study period was directly consumed by ET and the annual average dryness index (ET/P) generally increased for 2000-2014 over the Loess Plateau.

\subsubsection{Spatial variations}

In general, the mean annual precipitation on the Loess Plateau was lower in the northwest and higher in the southeast (Fig. 4). During the pre-GFG stage (1982-1999, Fig. 4a), the mean annual precipitation was $429 \mathrm{~mm}$ and the relatively high-precipitation area $(>450 \mathrm{~mm})$ was $2.5 \times 10^{5} \mathrm{~km}^{2}$ (about $40 \%$ of the region). Since 2000 (Fig. 4b), the mean annual precipitation increased to 462 $\mathrm{mm}$ and the relatively high-precipitation area was $2.7 \times 10^{5} \mathrm{~km}^{2}$. Comparing Figures $4 \mathrm{a}$ and $\mathrm{b}$, we can also conclude the area with relatively low-precipitation $(<300 \mathrm{~mm})$ increased from $1.0 \times 10^{5}$ $\mathrm{km}^{2}$ in the pre-GFG to $1.2 \times 10^{5} \mathrm{~km}^{2}$ in the post-GFG, especially in the northwest region of the study area.

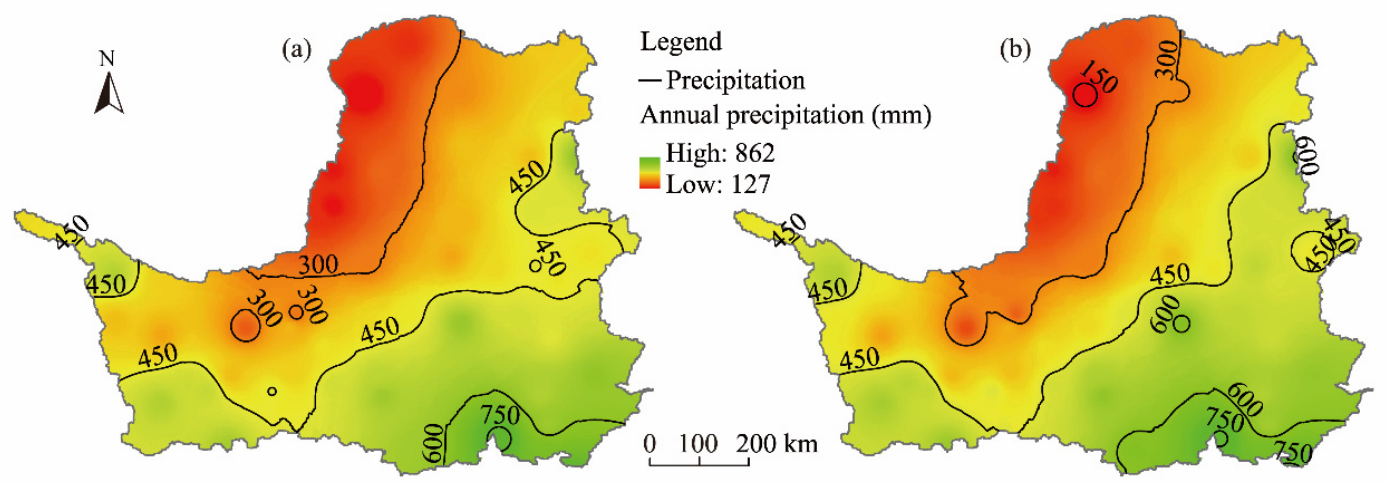

Fig. 4 Spatial change of mean annual $P$ during two sub-periods: (a) before GFG project implementation (19821999), and (b) during GFG project implementation (2000-2014)

Zones with high potential evapotranspiration $\left(\mathrm{ET}_{0}>1000 \mathrm{~mm}\right)$ were mainly distributed in the northern and southeastern regions of the study area (Fig. 5). There was a significant overall increase in $\mathrm{ET}_{0}$ for 1982-2014. During 1982-1999 (Fig. 5a), the total high evapotranspiration area was $2.3 \times 10^{5} \mathrm{~km}^{2}$ (38\% of the region), compared to $3.1 \times 10^{5} \mathrm{~km}^{2}$ from 2010 onward $(49 \%$ of the region, Fig. 4d). The middle and southeast region also showed the most obvious changes in $\mathrm{ET}_{0}$.

The annual average NDVI showed an increasing trend from 1982 to 2014; vegetation restoration areas were mainly concentrated in the southeastern Loess Plateau. From 1982 to 1999 (Fig. 6a), the annual average NDVI was 0.31 , and only $31 \%$ of the region reached moderate vegetation coverage (NDVI $>0.50$ ). Following the GFG implementation, the annual average NDVI slightly increased to 0.34 (Fig. 6b). The area of moderate vegetation coverage increased by about $6.2 \times 10^{5} \mathrm{~km}^{2}$ from 2000 to 2014 , which was similar to the results reported by Li et al. (2016).

The areas with obvious changes in $\mathrm{P}, \mathrm{ET}_{0}$ and NDVI were concentrated in the southeastern 
region of the Loess Plateau, where ET also changed the most (Fig. 7). Similar to precipitation, ET was the lowest in the northwest and the highest in the southeast. Although there was a slight increasing trend in ET for 1982-2014, it was not statistically significant based on the Mann-Kendall test. During 1982-1999, about a quarter of the area recorded an annual average ET $>400 \mathrm{~mm}$, while this reached about a third for 2000-2014.
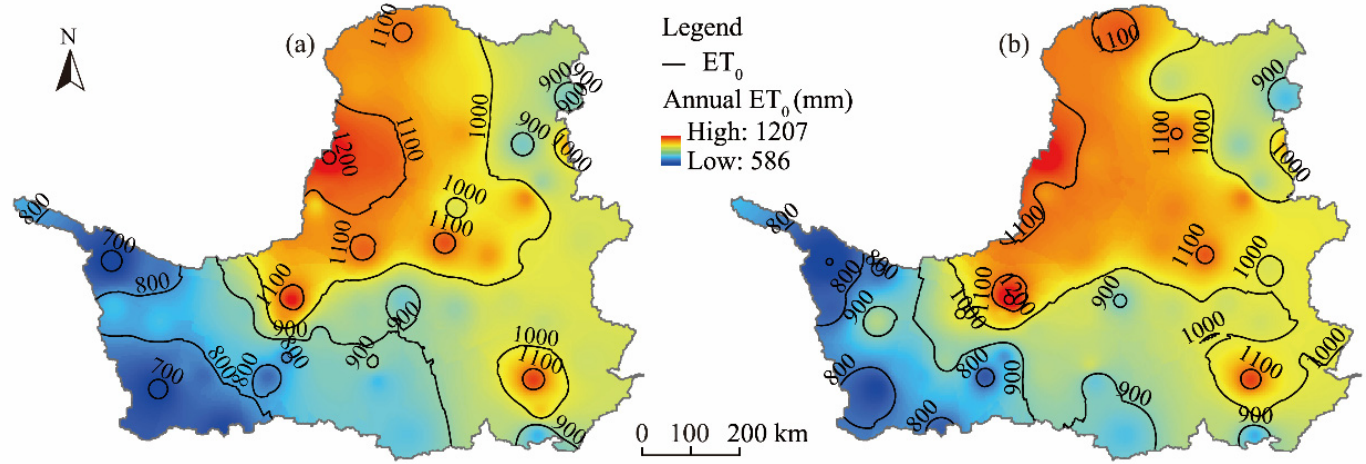

Fig. 5 Spatial change of annual average $\mathrm{ET}_{0}$ during two sub-periods: (a) before GFG project implementation (1982-1999), and (b) during GFG project implementation (2000-2014)

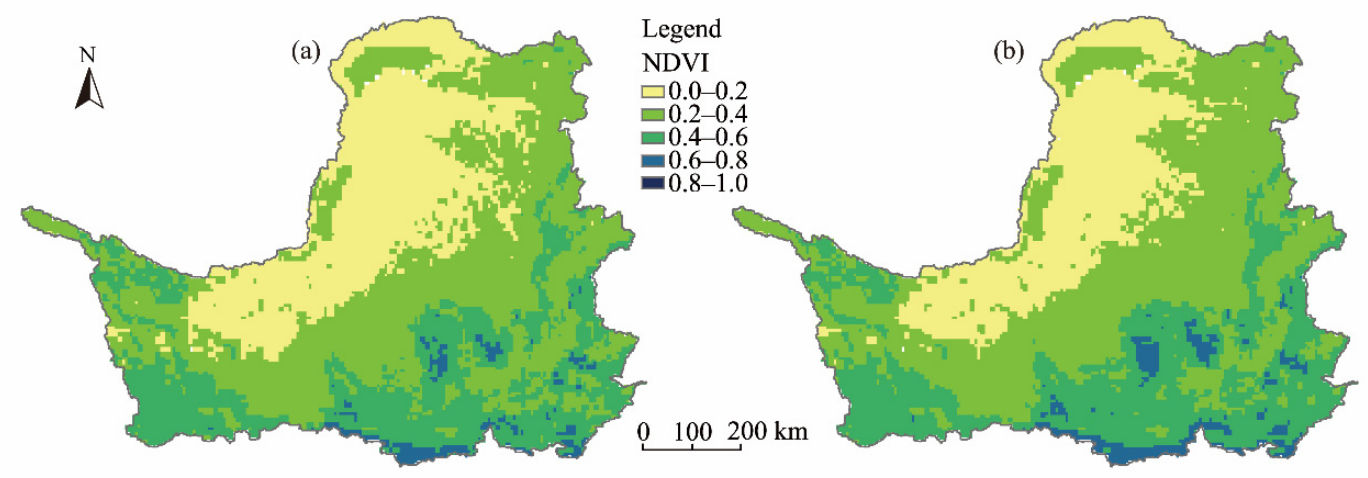

Fig. 6 Spatial change of annual average NDVI during two sub-periods: (a) before GFG project implementation (1982-1999), and (b) during GFG project implementation (2000-2014)

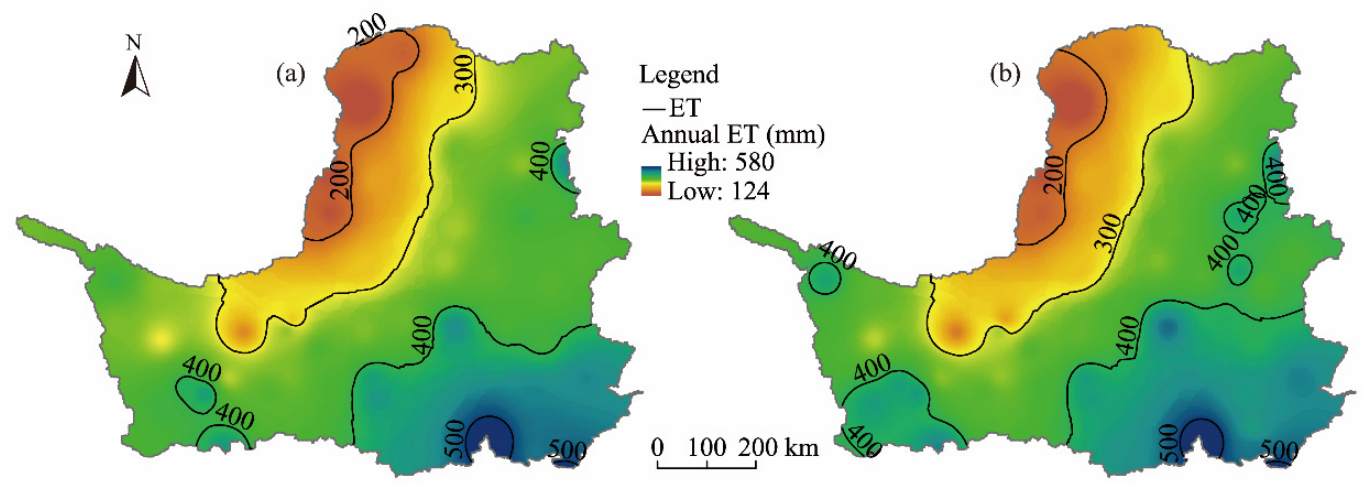

Fig. 7 Spatial change of annual average ET during two sub-periods: (a) before GFG project implementation (1982-1999), and (b) during GFG project implementation (2000-2014) 


\subsection{Quantitative estimation of dominant factors influencing ET}

As the areas with obvious changes in ET are similar to those for the three control factors (precipitation, regional $\mathrm{ET}_{0}$ and vegetation condition), it was difficult to identify the influence of these factors using only spatial correlation analysis. Therefore, we used Equation 6 to estimate ET changes due to these factors. As shown in Table 1, the estimated ET calculated by the Budyko equation matches well with observed ET (Equation 11) in both sub-periods, with an $R^{2}$ value of 0.85 . The difference in the change trend between estimated ET and observed ET in both periods is within $11.5 \%$. In general, for 1982-2014, precipitation was the primary factor affecting ET on the Loess Plateau, with a contribution rate of $61.5 \%$, far greater than $\mathrm{ET}_{0}$ or $n$. However, this was not consistent over time. For 1982-1999, the contribution rate of $P$ was $-163.9 \%$, indicating that declining precipitation was the major factor affecting ET. However, as the climate became wetter, precipitation had a positive contribution to ET during 2000-2014 at an average contribution rate of $117.4 \%$.

Vegetation condition was the second important factor influencing ET for 1982-2014; as this gradually increased throughout the study period, it always had a positive contribution to ET. Meanwhile, $\mathrm{ET}_{0}$ had the smallest effect on ET. Its contribution rate to ET during different periods was related to its change trend, similar to precipitation. During 1982-1999, $\mathrm{ET}_{0}$ followed an increasing trend such that its contribution rate to ET was positive, while after $2000, \mathrm{ET}_{0}$ showed a decreasing trend.

Table 1 Attribution analyses of $P, \mathrm{ET}_{0}$ and $n$ on ET change

\begin{tabular}{|c|c|c|c|c|c|c|c|c|}
\hline \multirow{2}{*}{ Period } & \multirow{2}{*}{$\frac{d(P-R)}{d t}$} & \multirow{2}{*}{$\frac{d \mathrm{ET}}{d t}$} & \multirow{2}{*}{$\frac{\partial \mathrm{ET}}{\partial P} \frac{d P}{d t}$} & \multirow{2}{*}{$\frac{\partial \mathrm{ET}}{\partial \mathrm{ET}_{0}} \frac{d \mathrm{ET}_{0}}{d t}$} & \multirow{2}{*}{$\frac{\partial \mathrm{ET}}{\partial n} \frac{d n}{d t}$} & \multicolumn{3}{|c|}{ Contribution rates (\%) of $P, \mathrm{ET}_{0}$ and $n$ on ET } \\
\hline & & & & & & $P$ & $\mathrm{ET}_{0}$ & $n$ \\
\hline 1982-1999 & 0.69 & 0.72 & -1.18 & 0.83 & 1.07 & -163.89 & 115.28 & 148.61 \\
\hline $2000-2014$ & 0.25 & 0.22 & 0.27 & -0.09 & 0.04 & 117.39 & -39.13 & 17.39 \\
\hline $1982-2014$ & 0.28 & 0.26 & 0.16 & 0.03 & 0.07 & 61.54 & 11.54 & 26.92 \\
\hline
\end{tabular}

Note: $P$, annual precipitation $(\mathrm{mm}) ; R$, runoff depth $(\mathrm{mm}) ; \mathrm{ET}$, annual land evapotranspiration $(\mathrm{mm}) ; \mathrm{ET}_{0}$, annual potential evapotranspiration (mm); $n$, catchment landscape characteristics; $t$, given time interval (year). $d(P-R) / d t$ and $d$ ET/dt represent changes in observed ET and estimated ET for a given time interval.

In general, precipitation was the dominant factor influencing changes in ET during 1981-1999, especially in the northern and southern study area. ET changes at 11 meteorological stations were controlled by vegetation, which are mainly distributed in the middle of the study area (Fig. 8a). In comparison, for 2000-2014, precipitation-dominated stations increased to 50 (Fig. 8b). These results clearly showed that precipitation, rather than $\mathrm{ET}_{0}$ and vegetation condition, was the factor controlling changes in ET throughout the study area for 1982-2014.

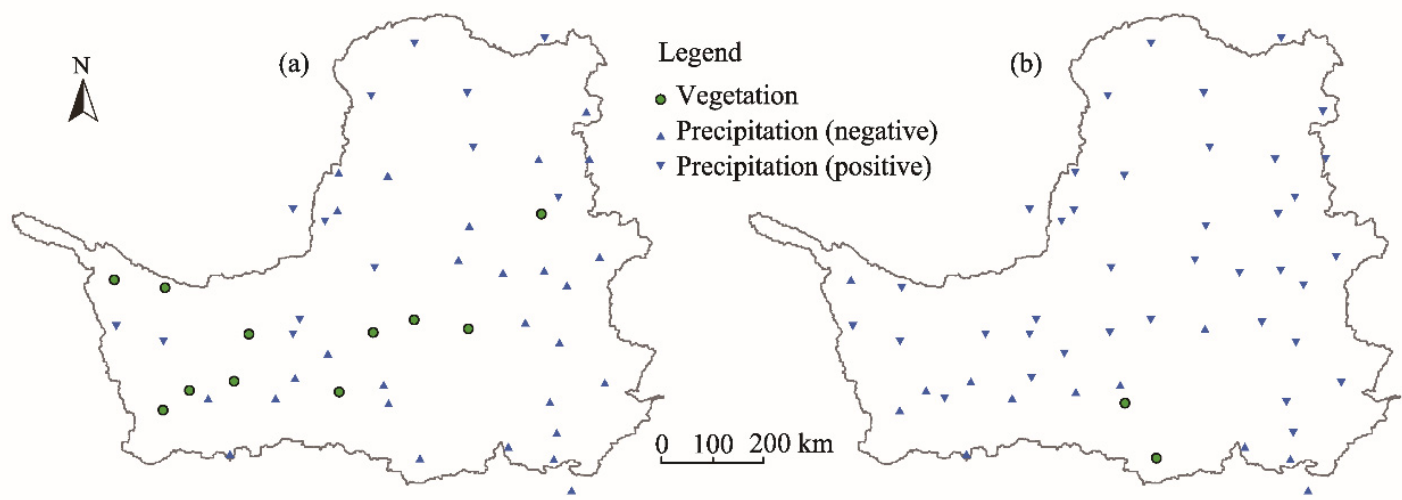

Fig. 8 Spatial change of the most dominant factor contributing to ET change at 52 meteorological stations in two stages of the GFG project: (a) before implementation (1982-1999) and (b) during implementation (20002014) 
Thus, we conclude that precipitation is the dominant influence factor on ET within the Loess Plateau. During 1982-2014, the attribution of climate change $\left(P\right.$ and $\left.\mathrm{ET}_{0}\right)$ and vegetation restoration $(n)$ to ET was $73.1 \%$ and $26.9 \%$, respectively; precipitation was the most important climate factor influencing ET (61.5\%). Consequently, although vegetation coverage increased significantly after the GFG project was launched in 1999, precipitation remains the dominant factor in the Loess Plateau's water cycle. This is consistent with findings in other arid and semi-arid regions (Xu et al., 2011).

\subsection{Reliability of results}

In this study, we analyzed spatio-temporal variations in precipitation, $\mathrm{ET}_{0}, \mathrm{NDVI}$ and $\mathrm{ET}$. The research results show that annual precipitation and $\mathrm{ET}_{0}$ in the Loess Plateau slightly decreased and clearly increased, respectively, from 1982 to 2014. However, contrary to the overall trend, precipitation and $\mathrm{ET}_{0}$, respectively, showed a slightly increasing and decreasing trends during 2000-2014. The annual ET for 1982-2014 showed a slightly increasing trend; however, this was not statistically significant.

Our results for precipitation and $\mathrm{ET}_{0}$ matched previous studies with respect to climatic variables in the study area. For instance, Xin et al. (2011) studied the spatio-temporal change of precipitation during 1956-2008 in the Loess Plateau, showing that annual precipitation decreased significantly over the entire period but showed an upward trend after 2000. Changes in precipitation during 1961-2016 over the Loess Plateau were analyzed by Sun et al. (2015), whose research is similar to that of Xin et al (2011). Li et al. (2012a) analyzed the effects of extreme precipitation change and temperature change in the Loess Plateau and found that more intense precipitation would occur during the $21^{\text {st }}$ century, with total annual precipitation expected to slightly increase. The spatial variability in precipitation on the Loess Plateau was also studied by Miao et al. (2016), who found that the southeastern region of the study area had a higher potential for flooding, while the northwestern region had a higher potential for drought. Li et al. (2012b) used the P-M equation to calculate $\mathrm{ET}_{0}$ for 1961-2010 and also used the Hadley Centre Coupled Model to predict $\mathrm{ET}_{0}$. Their study concluded that $\mathrm{ET}_{0}$ would significantly increase due to an upward trend in temperature and a downward trend in relative humidity in the Loess Plateau.

Nevertheless, our results are not consistent with those of Jin et al. (2017), who analyzed ET for 2000-2012 using evapotranspiration model-based remote sensing and used control model variables to separate vegetation restoration and climate variation controls on ET. Their results suggested that vegetation restoration is the dominant driving factor for interannual change of ET, and that higher-trending ET values coincide with increases in precipitation, implying possible pressure on water availability. However, Gao et al. (2016) produced results consistent with our research by investigating the spatio-temporal distributions of ET using the Yang's equation in the Loess Plateau. They found that regional precipitation is the factor controlling changes in regional ET, which showed a significant increasing trend for 1990-2014. Contrary to Jin et al. (2017), Gao et al. (2016) argued that the increase rate of ET was lower than that of precipitation in the same period. Feng et al. (2012) built a month-scale ET model based on $P, \mathrm{ET}_{0}$ and leaf area index in the Loess Plateau. Although there were some discrepancies between estimated ET and observed ET, the calculation results of the model indicated that precipitation is the factor controlling ET in the study area (Feng et al., 2012). In this study, we used Budyko-based partial differential methods to analyze contributors to ET change because this approach involves relatively simple calculations and includes a basic physical mechanism (Wu et al., 2016); we therefore consider the results acceptable and reliable. Based on our research, precipitation is a controlling factor for ET change in the Loess Plateau, with a contribution rate of $61.5 \%$. Budyko-based partial differential methods were also used to analyze runoff changes in the Loess Plateau (Liang et al., 2015). However, in contrast with our research results, Liang et al. suggested that ecological restoration played a key role in runoff change.

Although the model used in this study considers non-liner interactions among precipitation, $\mathrm{ET}_{0}$ and vegetation condition, the vegetation condition is affected by regional precipitation to some extent (Wang et al., 2010), so our results may underestimate the contribution of 
precipitation to ET. In addition, the large spatial resolution of the NDVI data and meteorological data may introduce other errors into the contribution analysis. Moreover, the Budyko hypothesis is a method for calculating long-term actual ET. In this study, the study period was divided into two sub-periods, 1982-1999 and 2000-2014, based on the vegetation restoration project. Although the duration of the two sub-periods exceeded 15 years, some errors may still be present in the results.

\section{Conclusions}

This study analyzed the temporal and spatial evolution of the regional annual ET in the pre-GFG (1982-1999) and post-GFG (2000-2014) periods in the Loess Plateau using the Budyko framework. We concluded that the annual ET displayed a slight increasing trend with an overall value of $0.28 \mathrm{~mm} / \mathrm{a}(\mathrm{Z}=0.33$, not passing the $90 \%$ significance level) during the study period. For 1982-1999, the annual mean ET was $353.2 \mathrm{~mm}$ and the increase rate was $0.69 \mathrm{~mm} / \mathrm{a}$, but for 2000-2014, the annual mean ET was $356.5 \mathrm{~mm}$ and the increase rate was $0.25 \mathrm{~mm} / \mathrm{a}$. Using Budyko-based partial differential methods, we also found that precipitation was the most important factor affecting the change in actual ET for 1982-2014 in the study area; the average rates of contribution of precipitation, potential evapotranspiration and vegetation restoration on ET change were $61.5 \%, 11.5 \%$ and $26.9 \%$, respectively. Therefore, although vegetation coverage increased significantly after the Grain for Green project was launched in 1999, precipitation remains the dominant factor controlling water cycle processes in the Loess Plateau.

With climate change and increased human activities, ensuring a stable water cycle process is becoming an unprecedented challenge for the arid Loess Plateau. Based on our research, precipitation rather than the vegetation restoration project is the factor controlling ET changes during 1982-2014. However, the impact of vegetation change on the nexus of carbon, energy and water cycles should be recognized. Moving forward, comprehensive studies that explore all aspects of the impact of vegetation change in the Loess Plateau would be in help to improve the water and sustainability of the region.

\section{Acknowledgements}

This work was supported by the National Key Research and Development Program of China (2016YFC0401300), the Basic Research Project of China Institute of Water Resources and Hydropower Research (WR0145B342019) and the National Science Fund for Distinguished Young Scholars (51625904).

\section{References}

Budyko M I. 1961. The heat balance of the Earth's surface. Soviet Geography, 2(4): 3-13.

Budyko M I. 1969. The effect of solar radiation variations on the climate of the Earth. Tellus, 21: 611-619.

Chirouze J, Boulet G, Jarlan L, et al. 2013. Intercomparison of four remote-sensing-based surface energy balance methods to retrieve surface evapotranspiration and water stress of irrigated fields in semi-arid climate. Hydrology and Earth System Sciences, 18: 1165-1188.

Droogers P. 2000. Estimating actual evapotranspiration using a detailed agro-hydrological model. Journal of Hydrology, 229(12): $50-58$.

Fang X, Ren L, Li Q, et al. 2012. Estimating and validating basin-scale actual evapotranspiration using MODIS images and hydrologic models. Hydrology Research, 43(1-2): 156-166.

Fang X, Zhao W, Wang L, et al. 2016. Variations of deep soil moisture under different vegetation types and influencing factors in a watershed of the Loess Plateau, China. Hydrology and Earth System Sciences, 20: 3309-3323.

Feng H, Zou B, Luo J. 2017. Coverage-dependent amplifiers of vegetation change on global water cycle dynamics. Journal of Hydrology, 550: 220-229.

Feng X M, Sun G, Fu B J, et al. 2012. Regional effects of vegetation restoration on water yield across the Loess Plateau, China. Hydrology and Earth System Sciences, 16(8): 2617-2628.

Feng X, Fu B, Lu N, et al. 2013. How ecological restoration alters ecosystem services: an analysis of carbon sequestration in China's Loess Plateau. Scientific Reports, 3: 2846. 
Feng X, Fu B, Piao S, et al. 2016. Revegetation in China's Loess Plateau is approaching sustainable water resource limits. Nature Climate Change, 6: 1019-1022.

Fu B, Yu L, Lü Y, et al. 2011. Assessing the soil erosion control service of ecosystems change in the Loess Plateau of China. Ecological Complexity, 8(4): 284-293.

Gao X, Sun M, Zhao Q, et al. 2016. Actual ET modelling based on the Budyko framework and the sustainability of vegetation water use in the loess plateau. Science of the Total Environment, 579: 1550-1559.

Gao Z L, Yong-Hong LI, Jua XU, et al. 2009. Research on eco-construction and control measures of soil and water loss in the loess plateau. Science Technology \& Industry, 9(10): 1-12. (in Chinese)

Jin Z, Liang W, Yang Y, et al. 2017. Separating vegetation greening and climate change controls on evapotranspiration trend over the loess plateau. Scientific Reports, 7: 8191.

Jung M, Reichstein M, Ciais P, et al. 2010. Recent decline in the global land evapotranspiration trend due to limited moisture supply. Nature, 467: 951-954.

Li S, Liang W, Fu B, et al. 2016. Vegetation changes in recent large-scale ecological restoration projects and subsequent impact on water resources in China's Loess Plateau. Science of the Total Environment, 569-570: 1032-1039.

Li Z, Zheng F L, Liu W Z. 2012. Spatiotemporal characteristics of reference evapotranspiration during 1961-2009 and its projected changes during 2011-2099 on the Loess Plateau of China. Agricultural \& Forest Meteorology, 154-155: 147-155.

Li Z, Zheng F L, Liu W Z, et al. 2012. Spatially downscaling GCMs outputs to project changes in extreme precipitation and temperature events on the Loess Plateau of China during the $21^{\text {st }}$ Century. Global and Planetary Change, 83: 65-73.

Liang W, Bai D, Wang F, et al. 2015. Quantifying the impacts of climate change and ecological restoration on streamflow changes based on a Budyko hydrological model in China's Loess Plateau. Water Resources Research, 51(8): 6500-6519.

Liu Q, Yang Z. 2010. Quantitative estimation of the impact of climate change on actual evapotranspiration in the Yellow River Basin, China. Journal of Hydrology, 395(3-4): 226-234.

Lü Y, Fu B, Feng X, et al. 2012. A policy-driven large scale ecological restoration: Quantifying ecosystem services changes in the loess plateau of China. PLoS ONE, 7(2): e31782.

Meng C L, Li Z L, Zhan X, et al. 2009. Land surface temperature data assimilation and its impact on evapotranspiration estimates from the Common Land Model. Water Resources Research, 45(2): 335-345.

Miao C Y, Sun Q H, Duan Q Y, et al. 2016. Joint analysis of changes in temperature and precipitation on the Loess Plateau during the period 1961-2011. Climate Dynamics, 47(9-10): 3221-3234.

Nash L L, Gleick P H. 1991. Sensitivity of streamflow in the Colorado Basin to climatic changes. Journal of Hydrology, 125(34): 221-241.

Ning T T, Li Z, Liu W Z, et al. 2017. Vegetation dynamics and climate seasonality jointly control the interannual catchment water balance in the Loess Plateau under the Budyko framework. Hydrology and Earth System Sciences, 21: 1515-1526.

Oki T, Kanae S. 2006. Global hydrological cycles and world water resources. Science, 313(5790): 1068-1072.

Roderick M L, Farquhar G D. 2011. A simple framework for relating variations in runoff to variations in climatic conditions and catchment properties. Water Resources Research, 47(12): 667-671.

Sun Q H, Miao C Y, Duan Q Y, et al. 2015. Temperature and precipitation changes over the Loess Plateau between 1961 and 2011, based on high-density gauge observations. Global and Planetary Change, 132: 1-10.

Wang T M, Kou X J, Xiong Y C, et al. 2010. Temporal and spatial patterns of NDVI and their relationship to precipitation in the Loess Plateau of China. International Journal of Remote Sensing, 31(7): 1943-1958.

Wu C, Hu B X, Huang G, et al. 2017. Effects of climate and terrestrial storage on temporal variability of actual evapotranspiration. Journal of Hydrology, 549: 388-403.

Wu J, Miao C, Wang Y, et al. 2016. Contribution analysis of the long-term changes in seasonal runoff on the Loess Plateau, China, using eight Budyko-based methods. Journal of Hydrology, 545: 263-275.

Xin Z, Yu X, Li Q, et al. 2011. Spatiotemporal variation in rainfall erosivity on the Chinese Loess Plateau during the period 1956-2008. Regional Environmental Change, 11(1): 149-159.

Xu X, Yang D, Sivapalan M. 2012. Assessing the impact of climate variability on catchment water balance and vegetation cover. Hydrology and Earth System Sciences, 16: 43-58.

Xu X, Yang D, Yang H, et al. 2014. Attribution analysis based on the Budyko hypothesis for detecting the dominant cause of runoff decline in Haihe basin. Journal of Hydrology, 510: 530-540.

Yang D, Sun F, Liu Z, et al. 2006. Interpreting the complementary relationship in non-humid environments based on the Budyko and Penman hypotheses. Geophysical Research Letters, 33(18), 122-140.

Yang D, Sun F, Liu Z, et al. 2007. Analyzing spatial and temporal variability of annual water-energy balance in nonhumid regions of China using the Budyko hypothesis. Water Resources Research, 43(4): 436-451. 
Yang D, Shao W W, Yeh P J F, et al. 2009. Impact of vegetation coverage on regional water balance in the nonhumid regions of China. Water Resources Research, 45(7): 450-455.

Yang D, Zhang S L, Xu X Y. 2015. Attribution analysis for runoff decline in Yellow River Basin during past fifty years based on Budyko hypothesis. Scientia Sinica, 45: 1024-1034. (in Chinese)

Yang H, Yang D, Lei Z, et al. 2008. New analytical derivation of the mean annual water-energy balance equation. Water Resources Research, 44(3): 893-897.

Zhang B, Wu P, Zhao X, et al. 2014. Assessing the spatial and temporal variation of the rainwater harvesting potential (19712010) on the Chinese Loess Plateau using the VIC model. Hydrological Processes, 28(3): 534-544.

Zhang L, Dawes W R, Walker G R. 2001. Response of mean annual evapotranspiration to vegetation changes at catchment scale. Water Resources Research, 37(3): 701-708.

Zhang T, Peng J, Liang W, et al. 2016. Spatial-temporal patterns of water use efficiency and climate controls in China's Loess Plateau during 2000-2010. Science of the Total Environment, 565: 105-122.

Zhang X, Zhao W, Liu Y, et al. 2016. The relationships between grasslands and soil moisture on the Loess Plateau of China: A review. Catena, 145: 56-57.

Zhang Y, Peña-Arancibia J L, McVicar T R, et al. 2016. Multi-decadal trends in global terrestrial evapotranspiration and its components. Scientific Reports, 6: 19124

Zhang Y W, Deng L, Yan W M, et al. 2016. Interaction of soil water storage dynamics and long-term natural vegetation succession on the Loess Plateau, China. Catena, 137: 52-60.

Zhao G, Mu X, Wen Z, et al. 2013. Soil erosion, conservation, and eco-environment changes in the Loess Plateau of China. Land Degradation \& Development, 24(5): 499-510.

Zhao W, Fang X, Stefani D, et al. 2018. Factors influencing soil moisture in the Loess Plateau, China: a review. Earth and Environmental Science Transactions of the Royal Society of Edinburgh, 501-509. 


\section{Appendix}

Table S1 Catchments for validation and corresponding hydrological stations in the Loess Plateau

\begin{tabular}{ccccc}
\hline Catchment number & Station name & $\begin{array}{c}\text { Latitude } \\
\left({ }^{\circ} \mathrm{N}\right)\end{array}$ & $\begin{array}{c}\text { Longitude } \\
\left({ }^{\circ} \mathrm{E}\right)\end{array}$ & $\begin{array}{c}\text { Controls drainage area } \\
\left(\mathrm{km}^{2}\right)\end{array}$ \\
\hline 1 & Huangfu & 39.28 & 111.08 & 3218.37 \\
2 & Wenjiachuan & 38.26 & 110.45 & 8619.46 \\
3 & Qiaotou & 38.56 & 111.08 & 2858.06 \\
4 & Gaojiachuan & 38.15 & 110.29 & 5039.36 \\
5 & Houdacheng & 37.25 & 110.45 & 4160.03 \\
6 & Yanchuan & 36.53 & 110.11 & 3662.65 \\
7 & Ganguyi & 36.42 & 109.48 & 6051.70 \\
8 & Liujiahe & 35.12 & 108.50 & 4759.50 \\
10 & Qingyang & 36.00 & 107.53 & $13,665.46$ \\
11 & Maojiahe & 35.31 & 107.35 & 3617.06 \\
12 & Qing'an & 34.54 & 105.40 & $10,728.55$ \\
\end{tabular}

Table S2 Meteorological stations in the Loess Plateau

\begin{tabular}{|c|c|c|c|c|}
\hline \multicolumn{2}{|c|}{ Station } & \multirow{2}{*}{$\begin{array}{c}\text { Latitude } \\
\left({ }^{\circ} \mathrm{N}\right)\end{array}$} & \multirow{2}{*}{$\begin{array}{c}\text { Longitude } \\
\left({ }^{\circ} \mathrm{E}\right)\end{array}$} & \multirow{2}{*}{$\begin{array}{l}\text { Elevation } \\
\text { (m) }\end{array}$} \\
\hline Number & Name & & & \\
\hline 52765 & Menyuan & 37.23 & 101.37 & 2851.0 \\
\hline 52787 & Wushaolin & 37.12 & 102.52 & 3043.9 \\
\hline 52866 & Xining & 36.43 & 101.45 & 2295.2 \\
\hline 52876 & Minhe & 36.19 & 102.51 & 1814.8 \\
\hline 52895 & Jingyuan & 36.34 & 104.41 & 1399.3 \\
\hline 52983 & Yuzhong & 35.52 & 104.09 & 1875.4 \\
\hline 52984 & Linxia & 35.35 & 103.11 & 3324.3 \\
\hline 52986 & Lintao & 35.22 & 103.52 & 1887.8 \\
\hline 52996 & Huajialing & 35.23 & 105.00 & 2450.4 \\
\hline 53336 & Wulatezhongqi & 41.34 & 108.31 & 1289.8 \\
\hline 53446 & Baotou & 40.44 & 109.51 & 1069.1 \\
\hline 53463 & Huhehaote & 41.32 & 111.41 & 1701.0 \\
\hline 53478 & Youyu & 40.00 & 112.27 & 1271.2 \\
\hline 53513 & Linhe & 40.45 & 107.25 & 1040.8 \\
\hline 53519 & Huinong & 39.13 & 106.46 & 1511.5 \\
\hline 53529 & Eketuoqi & 39.06 & 107.59 & 1381.3 \\
\hline 53543 & Dongshen & 39.50 & 109.59 & 1459.0 \\
\hline 53564 & Hequ & 39.23 & 111.09 & 861.5 \\
\hline 53614 & Yinchuan & 38.29 & 106.13 & 1112.7 \\
\hline 53615 & Taole & 38.48 & 106.42 & 3368.3 \\
\hline 53646 & Yulin & 38.14 & 109.42 & 1976.5 \\
\hline 53663 & Wuzhai & 38.55 & 111.49 & 1179.4 \\
\hline 53664 & Xingxian & 38.28 & 111.08 & 1013.6 \\
\hline 53705 & Zhongning & 38.50 & 105.40 & 1562.8 \\
\hline 53723 & Yanchi & 37.47 & 107.24 & 3093.7 \\
\hline 53738 & Wuqi & 36.55 & 108.10 & 2951.0 \\
\hline 53740 & Hengshan & 37.56 & 109.14 & 1107.5 \\
\hline
\end{tabular}


Continued

\begin{tabular}{|c|c|c|c|c|}
\hline \multicolumn{2}{|c|}{ Station } & \multirow{2}{*}{$\begin{array}{c}\text { Latitude } \\
\left({ }^{\circ} \mathrm{N}\right)\end{array}$} & \multirow{2}{*}{$\begin{array}{l}\text { Longitude } \\
\left({ }^{\circ} \mathrm{E}\right)\end{array}$} & \multirow{2}{*}{$\begin{array}{l}\text { Elevation } \\
\text { (m) }\end{array}$} \\
\hline Number & Name & & & \\
\hline 53754 & Suide & 37.30 & 110.13 & 928.5 \\
\hline 53764 & Lishi & 37.40 & 111.06 & 928.5 \\
\hline 53772 & Taiyuan & 37.47 & 112.33 & 3093.7 \\
\hline 53806 & Haiyuan & 36.34 & 105.39 & 1399.3 \\
\hline 53810 & Tongxin & 36.59 & 105.54 & 1345.2 \\
\hline 53817 & Guyuan & 36.00 & 106.16 & 1752.8 \\
\hline 53821 & Huanxian & 36.35 & 107.18 & 1256.0 \\
\hline 53853 & Xixian & 36.42 & 110.57 & 1053.7 \\
\hline 53863 & Jiexiu & 37.02 & 111.55 & 745.8 \\
\hline 53868 & Linfen & 36.04 & 111.30 & 450.3 \\
\hline 53903 & Xiji & 35.58 & 105.43 & 1921.4 \\
\hline 53915 & Pingliang & 35.33 & 106.40 & 1348.2 \\
\hline 53923 & Xifeng & 35.44 & 107.38 & 1421.9 \\
\hline 53929 & Changwu & 35.12 & 107.48 & 1206.8 \\
\hline 53942 & Luochuan & 36.36 & 109.30 & 958.8 \\
\hline 53959 & Yunchen & 35.02 & 111.01 & 375.9 \\
\hline 53975 & Yangchen & 35.29 & 112.24 & 658.8 \\
\hline 56080 & Hezuo & 35.00 & 102.54 & 2910.5 \\
\hline 56093 & Minxian & 34.26 & 104.01 & 2315.8 \\
\hline 57034 & Wugong & 34.15 & 108.13 & 449.1 \\
\hline 57046 & Huashan & 34.29 & 110.05 & 2064.9 \\
\hline 57051 & Sanmenxia & 34.48 & 111.12 & 411.8 \\
\hline 57067 & Lushi & 34.03 & 111.02 & 569.9 \\
\hline 57071 & Mengjin & 39.18 & 112.26 & 1092.4 \\
\hline 57077 & Luanchuan & 33.47 & 111.36 & 751.5 \\
\hline
\end{tabular}

